\title{
Obstrüktif Uyku Apne Semptomları ile Uyku Laboratuvarına Başvuran Hastalarda Hastane Anksiyete Depresyon Skorlarının Semptomlar ve Polisomnografik Bulgular ile ilişkisi
}

\section{The Association of the Hospital Anxiety and Depression Scores with the Symptoms and Polysomnography Findings in Patients Referred with the Symptoms of Obstructive Sleep Apnea Syndrome}

\author{
Banu Salepçi, Gülten Aktin Güngör, Elif Torun Parmaksız, Ali Fidan, Nesrin Kıral, Sevda Şener Cömert, Coşkun Doğan \\ Dr. Lütfi Kırdar Kartal Eğitim ve Araştırma Hastanesi, Göğüs Hastalıkları Kliniği, Istanbul, Türkiye
}

\section{Öz}

Amaç: Obstrüktif uyku apne sendromu (OUAS) ile depresyon ve anksiyete ilişkisi pek çok çalışmada gösterilmiş olmakla birlikte bu ilişki tam olarak anlaşılamamıştır. Çalışmamızda OUAS semptomları ile laboratuvarımıza refere edilen hastalarda hastane anksiyete depresyon (HAD) skorları ile semptomlar ve polisomnografi (PSG) bulguları arasındaki ilişkiyi araştırmayı amaçladık.

Gereç ve Yöntem: Çalışmaya uyku laboratuvarına horlama, tanıklı apne ve gündüz aşırı uykululuk semptomları ile refere edilen, ilk gece PSG yapılan hastalar dahil edildi. Okuma yazması olmayan hastalar çalışmaya alınmadı. Tüm gece PSG yapıldıktan sonra ertesi sabah hastaların semptomları ve ek hastalıkları sorgulandı. Vücut kitle indeksleri (VKI) hesaplandı. Epworth uykuluk skalası ve HAD skalası hastaların kendileri tarafından dolduruldu. Epworth, anksiyete ve depresyon skorları hesaplandı. Hastalar skorlarına göre kategorize edildi. HAD skorlarına göre semptomlar, ek hastalıklar ve PSG bulguları açısından karşılaştıııldı. Ayrıca HAD skorları ile semptomlar, PSG bulguları ve Epworth skoru (ES) arasındaki korelasyona bakıldı.

Bulgular: Çalışmaya alınan 149 olgunun ortalama yaşı $48 \pm 11$, ortalama VKI $31 \pm 5$ ve \%63'ü erkekti. Olguların 127'sinde (\%85) OUAS tespit edildi. Otuz iki (\%21) olguda depresyon olasılığı yüksek [depresyon skoru (DS) $>10), 24$ 'ünde (\%16) anksiyete olasilığı yüksek (AS >10) bulundu. DS $\leq 7$ ve $>7$ olanlar karşılaştııılığında; DS $>7$ olanlarda ES ve astım hastalık oranı anlamlı yüksek bulundu (sırasıyla $p=0,019 ; p=0,015$ ). Olguların diğer demografik özellikleri, semptomları ve PSG bulguları açısından fark yoktu $(p>0,05)$. AS $>10$ olanlarda AS $\leq 10$ olanlara göre PSG'de minimum oksijen satürasyonu $\left(\mathrm{minSpO}_{2}\right)$ anlamlı olarak daha düşük bulundu $(p=0,005)$. Diğer parametreler açısından fark yoktu $(p>0.05)$. DS ile yaş, kadın cinsiyet ve ortalama oksijen satürasyonu; AS ile kadın cinsiyet, VKI, ES ve gündüz aşırı uykululuk arasında korelasyon mevcuttu.

Sonuç: Çalışmamızda hastane anksiyete depresyon skoru ile OUAS varlığı ve apne hipopne indeksi arasında anlamlı bir ilişki bulunmadı. Olgularımızda depresyon ve anksiyete skorları ile ilişkili en önemli faktör gündüz aşırı uykululuk olarak tespit edildi.

Anahtar Kelimeler: Obstrüktif uyku apne sendromu, hastane anksiyete depresyon skalası, gündüz aşırı uykululuk

\begin{abstract}
Objective: Several studies have investigated the association between obstructive sleep apnea syndrome (OSAS) and depression and anxiety; however, the relationship is still not understood very well. In this study we aimed to investigate the association between the hospital anxiety and depression (HAD) scores and the symptoms and polysomnographic (PSG) findings in patients referred with OSAS symptoms.

Materials and Methods: Patients who referred with snoring, witnessed apnea and daytime sleepiness symptoms and patients who had full-night PSG were included in this study. Illiterate patients were not included in the study. Epworth sleepiness scale and HAD scores was self-administered by the patients. Patients were compared according to HAD scores for symptoms, comorbidities, and PSG findings. Also, the correlation between HAD and PSG findings, symptoms and Epworth scores (ES) of the patients were analyzed.

Results: Out of 149 patients who included in the study mean age was $48 \pm 11$, mean body mass index (BMI) was $31 \pm 5$, and $63 \%$ were male. Of the patients $127(85 \%)$ had OSAS. Of the patients $32(21 \%)$ had a high likelihood of depression (DS >10) and $24(16 \%)$ of anxiety (AS $>10)$. ESS and asthma rate were significantly higher in DS $>7$ subjects compared to $D S<7$ ( $p=0.019, p=0.015$, respectively). Minimum oxygen saturation $\left(\mathrm{minSpO}_{2}\right)$ in PSG was found significantly lower in AS $>10$ subjects compared to AS $<10$ subjects $(p=0.005)$. There were no difference concerning other parameters ( $p>0.05)$. There were correlations between DS and age, female gender and mean oxygen saturation; AS and female gender, BMI, ES and excessive daytime sleepiness.

Conclusion: We did not find any association between hospital anxiety depression score and presence of OSAS and apnea hypopnea index in our study. Excessive daytime sleepiness was found as the most important factor related to depression and anxiety scores in our patients. Keywords: Obstructive sleep apnea syndrome, hospital anxietydepression scale, excessive daytime sleepiness
\end{abstract}




\section{Giriş}

Obstrüktif uyku apne sendromu (OUAS), uykuda tekrarlayıcı olarak üst solunum yollarının kısmen veya tamamen kapanması sonucu oksijen desatürasyonu ve uyku bölünmesi ile karakterize yaygın bir hastalıktır $(1,2)$. Otuz-altmış yaş arası erkeklerin $\% 4$ 'ünde, kadınların \%2'sinde görülmektedir (3). Başlıca semptomları, horlama, tıkanma hissi ile uyanma, tanıklı apne ve gündüz aşırı uykululuktur (GAU). Ciddi kardiyovasküler ve serebrovasküler hastalıkların yanı sıra yaşam kalitesinde bozulma, mod değişiklikleri ve nörokognitif bozukluklara da yol açmaktadır $(1,2)$.

OUAS ve depresyon birlikteliği ilk kez 1977'de Guilleminault ve ark. (4) tarafından bildirilmiş olup takip eden yıllar boyunca pek çok çalışmada OUAS ile yaşam kalitesinde bozulma, depresyon ve mod değişiklikleri arasında pozitif bir ilişki olduğu gösterilmiştir (5-14). Yapılan çalışmalarda OUAS'li hastalarda depresyon sıklığı \%5-63 gibi değişen oranlarda bulunmuştur (11). Bu çalışmalar arasında depresyonun OUAS şiddeti ile ilişkili olduğunu tespit edenlerin yanı sıra hastalığın şiddetinden bağımsız olarak GAU gibi semptomlar ile ilişkili olduğunu gösterenler de mevcuttur. Bu tartışmalar bu konuda yapılmış ilk çalışmalardan günümüze kadar halen devam etmektedir $(5,9,11,13)$. Çalışmalarda hastalardaki mod değişikliklerini tespit etmek için yaşam kalitesi ve depresyonu ölçen çeşitli skalalar kullanılmıştır. Çoğu çalışmada OUAS ile depresyon ilişkisi gösterilmiş, az sayıda çalışmada ise hastane anksiyete depresyon skalası (HADS) kullanılarak hastaların anksiyete durumu da değerlendirilmiştir (12-14).

HADS, 1983'te Zigmond ve Snaith (15) tarafından geliştirilmiş, 2-5 dakikalık bir sürede cevaplanabilen, kolay anlaşılır, pek çok dilde uyumluluğu kanıtlanmış, kronik hastalıklarda depresyon ve anksiyete varlığının değerlendirilmesini sağlayan bir ankettir $(15,16)$. Aydemir ve ark. (17) tarafından da 1997 yılında Türkçe uyumluluğu kanıtlanmıştır.

Literatüre bakıldığında OUAS ile depresyon arasındaki ilişkinin semptomlara mı yoksa hastalığın şiddetine mi bağlı olduğu konusunda çelişkili sonuçlar mevcuttur, ayrıca anksiyete ve OUAS arasındaki ilişkiyi gösteren az sayıda çalışma yapılmıştır. Çalışmamızda OUAS semptomları ile uyku laboratuvarına refere edilen hastalarda HADS skorları ile semptomlar, ek hastalıklar ve polisomnografi (PSG) bulguları arasındaki ilişkiyi araştırmayı amaçladık.

\section{Gereç ve Yöntem}

Çalışmaya Eylül 2015-Haziran 2016 tarihleri arasında Kartal Dr. Lütfi Kırdar Eğitim ve Araştırma Hastanesi Göğüs Hastalıkları Kliniği Uyku Laboratuvarına horlama, tanıklı apne ve GAU semptomları ile refere edilen ve ilk gece PSG yapılan hastalar dahil edildi. Hastalardan imzalı onay formu alındı. Okuma yazması olmayan ve çalışmaya katılmayı kabul etmeyen hastalar çalışma dışı bırakıldı. Kesitsel bir çalışmadır.

Illk başvuruda hastaların semptomları, ek hastalıkları, sigara ve alkol alışkanlıkları sorgulandı, sorumlu hekim tarafından fizik muayeneleri yapıldı. Vücut kitle indeksleri (VKI) hesaplandı. Tüm demografik ve muayene bulgularını içeren formlar, sorumlu hekim tarafından dolduruldu.

Hastalara tüm gece PSG yapıldı (Comet Grass; Astro-Med, Inc., West Warwick, RI, USA and Viasys Cephalo-Pro, SomnoStar;
VIASYS Healthcare, Hoechberg, Germany). Sertrifikalı teknisyenler tarafından 6 kanal elektroensefalografi (F4-M1, C4-M1, O2-M1, F3-M2, C3-M2, O1-M2), elektrookülografi (E1-M2, E2-M2), bilateral tibia ve çene elektromiyografi, elektrokardiyografi, horlama sensörü, solunumsal olayların kaydı için nazal flow, oro-nazal termistör, respiratuvar indüktans pletismografi bağlanarak tüm gece kayıt alındı. Skorlama, sertifikalı uzman hekim tarafından Amerikan Uyku Tıbbı Akademisi (AASM) 2007 ve 2012 kurallarına göre yapıldı $(18,19)$. OUAS hastalık sınıflaması AASM 2014 Uluslararası Uyku Bozuklukları Sınıflaması'na göre yapıldı (20). AASM kriterlerine göre; apne hipopne indeksi $(\mathrm{AHI})<5$ olanlar normal, $\mathrm{AHI} \geq 5$ ve $<15$ olanlar hafif şiddette OUAS, $\mathrm{AHI} \geq 15$ ve $\leq 30$ olanlar orta şiddette OUAS, AHI >30 olanlar ağır şiddette OUAS olarak kabul edildi $(1,2)$. PSG testinin ertesi günü tüm olgular tarafından GAU semptomu şiddetinin belirlenmesi için Türkçe uyumluluğu kanıtlanmış Epworth Uykululuk Skalası (EUS) dolduruldu. EUS skoru 10'un üstünde olanlarda GAU olduğu kabul edildi $(21,22)$. Çalışmaya katılmayı kabul eden olgulara depresyon ve anksiyete varlığının belirlenmesi için Türkçe uyumluluğu kanıtlanmış HADS uygulandı. Skalayı hastalar kendileri doldurdu. Toplam 14 maddeden oluşan ankette tek maddeler anksiyete, çift maddeler depresyonun değerlendirilmesini sağlamaktadır. Anksiyete için alt kesme noktası 10, depresyon için alt kesme noktası 7'dir. Anksiyete skoru (AS) 10'un üstünde olan olgular, anksiyete olasılığı yüksek; depresyon skoru (DS) 7-10 arasında olanlar muhtemel depresif, 10'un üstünde olanlar depresyon olasılığı yüksek olarak kabul edilmektedir (15-17). Olgularımızın skorları da bu kriterlere göre değerlendirildi.

\section{İstatistiksel Analiz}

SPSS 17,0 programı kullanılarak veri girişi yapıldı. Kategorik değişkenlerin karşılaştırılması için ki-kare testi, ortalamaların karşılaştırılması için t-test, ortalama ve standart sapma kullanıldı. AS $\leq 10$ ve $>10$ olan olgular; DS $\leq 7$ ve $>7$ olan olgular, semptomları, demografik özellikleri, ek hastalıkları ve PSG bulgularına göre karşılaştıııldı. HADS skorları ile semptomlar, PSG bulguları ve EUS skorları arasındaki korelasyonu incelemek için Pearson ve Spearmen korelasyon analizleri kullanıldı. İstatistiksel anlamlıık için $\mathrm{p}<0,05$ değeri kabul edildi.

\section{Bulgular}

Çalışma periyodu içinde horlama, GAU, tanıklı apne semptomları ile uyku laboratuvarına başvuran ve ilk gece PSG yapılan 167 olgunun 18'i okuma yazma bilmediği veya çalışmaya katılmayı kabul etmediği için çalışma dışı bırakıldı. Çalışmaya dahil edilen 149 olgunun ortalama yaşı $48 \pm 11$, ortalama VKI $31 \pm 5$ ve $\% 63$ ü erkekti. Olguların 127'sinde (\%85) OUA tespit edildi. Kalan 22 olguda $\mathrm{AHI}<5$ bulunduğu için bu olgular basit horlama olarak

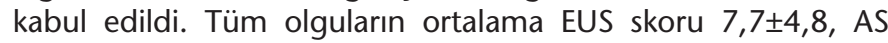
$7,7 \pm 4,3$ ve DS 7,3 $\pm 3,9$ bulundu. Altmış yedi olguda (\%45) depresyon olasılığı muhtemel (DS >7), 32 (\%21) olguda depresyon olasılığı yüksek (DS >10), 24 olguda da (\%16) anksiyete olasılığı yüksek (AS >10) bulundu. Olgularımızda en sık görülen semptomlar sırasıyla horlama $(\% 94,6)$, tanıklı apne $(\% 73,8)$, GAU $(\% 67,1)$ ve sabah baş ağrısı $(\% 53,7)$ idi. Ek hastalık oranı \%55 olup \%48,3'ü sigara içici, \%14,1'i alkol kullanıcıydı. PSG'de, ortalama uyku etkinliği \%79 14 , ortalama uyku latansı $23 \pm 27$ dakika, hızlı göz hareketi (REM) latansı $125 \pm 92$ dakika bulundu. 
Olgular DS'lerine göre demografik özellikleri, semptomları, ek hastalıkları ve PSG bulguları açısından karşılaştırıldığında; DS >7 olanlarda EUS skoru ve astım hastalık oranı anlamlı yüksek bulundu (sırasıyla $p=0,019 ; p=0,015$ ). Olguların diğer demografik özellikleri, semptomları, OUAS varlığı ve PSG bulguları açısından fark yoktu ( $p>0,05)$ (Tablo 1-3).

DS >10 olanlarda da DS $\leq 10$ olanlara göre astım oranı anlamlı yüksek, PSG'de ortalama oksijen satürasyonu anlamlı düşük bulundu (sırasıyla $p=0,034, p=0,037$ ). Olguların diğer demografik özellikleri, semptomları, OUAS varlığı ve PSG bulguları açısından fark yoktu ( $p>0,05)$.

Olgular AS'ye göre demografik özellikleri, semptomları, ek hastalıkları ve PSG bulguları açısından karşılaştırıldığında; AS $>10$ olanlarda AS $\leq 10$ olanlara göre sadece PSG'de minimum oksijen satürasyonu $\left.(\operatorname{minSpO})_{2}\right)$ anlamlı olarak daha düşük bulundu $(p=0,005)$. Diğer tüm parametreler ve OUAS varlığı açısından fark yoktu ( $p>0,05)$ (Tablo 4-6).

\begin{tabular}{|l|l|l|l|}
\hline \multicolumn{4}{|l|}{$\begin{array}{l}\text { Tablo 1. Olguların depresyon skorlarına göre demografik } \\
\text { özellikleri ve semptomları açısından karşılaştıılması }\end{array}$} \\
\hline & $\begin{array}{l}\text { Depresyon } \\
\text { skoru } \leq \mathbf{7} \\
\mathbf{n = 8 2}\end{array}$ & $\begin{array}{l}\text { Depresyon } \\
\text { skoru }>\text { 7 } \\
\mathbf{n = 6 7}\end{array}$ & $\mathbf{p}$ \\
\hline Yaş (yıl) ort./SS & $47 \pm 11$ & $49 \pm 11$ & 0,319 \\
\hline Cinsiyet (erkek \%) & 69 & 55 & 0,072 \\
\hline VKI (kg/m²) ort./SS & $31 \pm 5$ & $31 \pm 5$ & 0,976 \\
\hline Epworth skoru ort./SS & $7 \pm 4$ & $9 \pm 5$ & $\mathbf{0 , 0 1 9}$ \\
\hline Gündüz aşırı uykululuk \% & 63 & 72 & 0,288 \\
\hline Tanıklı apne \% & 73 & 75 & 0,841 \\
\hline Horlama \% & 92 & 97 & 0,296 \\
\hline Sabah baş ağrısı \% & 48 & 61 & 0,097 \\
\hline Sigara içenler \% & 49 & 48 & 0,254 \\
\hline Alkol kullanımı \% & 15 & 13 & 0,834 \\
\hline Ort./SS: Ortalama/standart sapma, VKi: Vücut kitle indeksi \\
\hline
\end{tabular}

\begin{tabular}{|l|l|l|l|}
\hline \multicolumn{4}{|c|}{$\begin{array}{l}\text { Tablo 2. Olguların depresyon skorlarına göre ek hastalıkları ve } \\
\text { obstrüktif uyku apne sendromu varlığı açıından karşılaştırılması }\end{array}$} \\
\hline & $\begin{array}{l}\text { Depresyon } \\
\text { skoru } \leq \mathbf{7} \\
\mathbf{n}=\mathbf{8 2}\end{array}$ & $\begin{array}{l}\text { Depresyon } \\
\text { skoru >7 } \\
\mathbf{n = 6 7}\end{array}$ & $\mathbf{p}$ \\
\hline Ek hastalıklar \% & 49 & 63 & 0,090 \\
\hline Hipertansiyon \% & 26 & 34 & 0,246 \\
\hline Diyabet \% & 15 & 19 & 0,438 \\
\hline Depresyon \% & 8 & 7 & 0,811 \\
\hline Hipotiroidi \% & 8 & 9 & 0,928 \\
\hline KOAH \% & 1 & 3 & 0,588 \\
\hline Astım \% & 4 & 15 & 0,015 \\
\hline Kardiyovasküler hastalık \% & 11 & 13 & 0,647 \\
\hline Diğerleri \% & 15 & 25 & 0,100 \\
\hline OUAS \% & 88 & 82 & 0,328 \\
\hline AHI >15 \% & 68 & 57 & 0,145 \\
\hline $\begin{array}{l}\text { KOAH: Kronik obstrüktif akciğer hastalığı, OUAS: Obstrüktif uyku apne } \\
\text { sendromu, AHI: Apne hipopne indeksi }\end{array}$ \\
\hline
\end{tabular}

Depresyon ve AS'leri ile yaş, cinsiyet, VKI, EUS, semptomlar ve PSG bulguları arasındaki korelasyona bakıldı. DS ile yaş ve kadın cinsiyet arasında pozitif, ortalama oksijen satürasyonu ile negatif korelasyon bulundu (sırasıyla $p=0,011, r=0,209 ; p=0,015$, $r=199 ; p=0,017, r=-196$ ). AS ile kadın cinsiyet, VKi, EUS ve GAU semptomu arasında pozitif korelasyon mevcuttu (sırasıyla $p<0,001, r=0,299 ; p=0,031, r=177 ; p=039, r=170 ; p=0,032$, $r=176$ ). AHI ile DS ve AS arasında korelasyon bulunmadı (Tablo 7).

\section{Tartışma}

$\mathrm{Bu}$ çalışmada horlama, tanıklı apne, GAU semptomları ile uyku laboratuvarına refere edilen hastalarda HADS skorları ile olguların semptomları, ek hastalıkları ve PSG bulguları

Tablo 3. Olguların depresyon skorlarına göre polisomnografi bulguları açısından karşılaştırılması

\begin{tabular}{|c|c|c|c|}
\hline & $\begin{array}{l}\text { Depresyon } \\
\text { skoru } \leq 7 \\
\mathrm{n}=82\end{array}$ & $\begin{array}{l}\text { Depresyon } \\
\text { skoru }>7 \\
\mathrm{n}=67\end{array}$ & $p$ \\
\hline Uyku etkinliği \% & $80 \pm 12$ & $77 \pm 16$ & 0,183 \\
\hline Uyku latansı (dakika) & $25 \pm 29$ & $19 \pm 24$ & 0,222 \\
\hline REM latansı (dakika) & $126 \pm 97$ & $125 \pm 89$ & 0,951 \\
\hline N1 \% & $6 \pm 5$ & $6 \pm 5$ & 0,874 \\
\hline N2 \% & $63 \pm 12$ & $66 \pm 14$ & 0,168 \\
\hline N3 \% & $15 \pm 8$ & $14 \pm 10$ & 0,408 \\
\hline REM \% & $15 \pm 7$ & $14 \pm 7$ & 0,344 \\
\hline AHI ort./SS & $30 \pm 28$ & $33 \pm 29$ & 0,621 \\
\hline Al ort./SS & $20 \pm 27$ & $21 \pm 26$ & 0,727 \\
\hline ODI ort./SS & $26 \pm 26$ & $28 \pm 27$ & 0,676 \\
\hline $\mathrm{MinSpO}_{2} \%$ & $83 \pm 7$ & $81 \pm 9$ & 0,075 \\
\hline Ortalama $\mathrm{SpO}_{2} \%$ & $93 \pm 2$ & $93 \pm 5$ & 0,139 \\
\hline PLMI ort./SS & $10 \pm 22$ & $13 \pm 24$ & 0,423 \\
\hline
\end{tabular}

Ort./SS: Ortalama/standart sapma, AHI: Apne hipopne indeksi, Ali: Apne indeksi, ODi: Oksijen desatürasyon indeksi, $\mathrm{MinSpO}_{2}$ : Minimum oksijen satürasyonu, PLMi: Periyodik bacak hareketleri indeksi

Tablo 4. Olguların anksiyete skorlarına göre demografik özellikleri ve semptomları açısından karşılaştırılması

\begin{tabular}{|l|l|l|l|}
\hline & $\begin{array}{l}\text { Anksiyete } \\
\text { skoru } \leq \mathbf{1 0} \\
\mathbf{n = 1 2 5}\end{array}$ & $\begin{array}{l}\text { Anksiyete } \\
\text { skoru }>\mathbf{1 0} \\
\mathbf{n = 2 4}\end{array}$ & $\mathbf{p}$ \\
\hline Yaş (yıl) ort./SD & $47 \pm 11$ & $52 \pm 13$ & 0,053 \\
\hline Cinsiyet (erkek \%) & 66 & 46 & 0,056 \\
\hline VKi (kg/m²) ort./SS & $31 \pm 5$ & $32 \pm 5$ & 0,401 \\
\hline Epworth skoru ort./SS & $8 \pm 5$ & $9 \pm 6$ & 0,436 \\
\hline Gündüz aşırı uykululuk \% & 65 & 79 & 0,170 \\
\hline Tanıklı apne \% & 74 & 71 & 0,716 \\
\hline Horlama \% & 93 & 100 & 0,236 \\
\hline Sabah baş ağrısı \% & 53 & 58 & 0,619 \\
\hline Sigara içenler \% & 50 & 42 & 0,521 \\
\hline Alkol kullanımı \% & 16 & 4 & 0,107 \\
\hline Ort./SS: Ortalama/standart sapma, VKi: Vücut kitle indeksi \\
\hline
\end{tabular}


arasındaki ilişkiye bakıldı. Olguların \%45'inde DS, \%24'ünde AS yüksek bulundu. DS yüksek olanlarda EUS skoru ve astımlı hasta oranı daha yüksek, AS yüksek olanlarda da $\mathrm{minSpO}_{2}$ daha düşük bulundu. DS ile yaş ve kadın cinsiyet arasında pozitif, ortalama $\mathrm{SpO}_{2}$ arasında negatif korelasyon vardı. AS ile de kadın cinsiyet, VKI, EUS skoru ve GAU semptomu arasında pozitif korelasyon bulundu. OUAS varlığı ve AHI ile HADS skorları arasında bir ilişki bulunmadı.

OUAS ile depresyon ve mod değişiklikleri arasında ilişki olduğunu gösteren pek çok çalışma mevcuttur. Bu konudaki ilk çalışmalardan Guilleminault ve ark.'nın (4) çalışmasında 25 apneli erkek hastanın \%24'ünde anksiyete ve depresyon

\begin{tabular}{|l|l|l|l|}
\hline \multicolumn{4}{|l|}{$\begin{array}{l}\text { Tablo 5. Olguların anksiyete skorlarına göre ek hastalıkları ve } \\
\text { obstrüktif uyku apne sendromu varlığı açısından karşılaştırılması }\end{array}$} \\
\hline & $\begin{array}{l}\text { Anksiyete } \\
\text { skoru } \leq \mathbf{1 0} \\
\mathbf{n = 1 2 5}\end{array}$ & $\begin{array}{l}\text { Anksiyete } \\
\text { skoru }>\mathbf{1 0} \\
\mathbf{n = 2 4}\end{array}$ & $\mathbf{p}$ \\
\hline Ek hastalıklar \% & 53 & 62 & 0,422 \\
\hline Hipertansiyon \% & 28 & 37 & 0,350 \\
\hline Diyabet \% & 16 & 21 & 0,373 \\
\hline Depresyon \% & 9 & 4 & 0,392 \\
\hline Hipotiroidi \% & 8 & 12 & 0,349 \\
\hline KOAH \% & 2 & 4 & 0,412 \\
\hline Astım \% & 7 & 17 & 0,135 \\
\hline Kardiyovasküler hastalık \% & 11 & 17 & 0,323 \\
\hline Diğerleri \% & 19 & 21 & 0,522 \\
\hline OUAS \% & 86 & 79 & 0,264 \\
\hline AHI >15 \% & 66 & 46 & 0,056 \\
\hline $\begin{array}{l}\text { KOAH: Kronik obstrüktif akciğer hastalığı, OUAS: Obstrüktif uyku apne } \\
\text { sendromu, AHi: Apne hipopne indeksi }\end{array}$ \\
\hline
\end{tabular}

Tablo 6. Olguların anksiyete skorlarına göre polisomnografi bulguları açısından karşılaştırılması

\begin{tabular}{|l|l|l|l|}
\hline & $\begin{array}{l}\text { Anksiyete } \\
\text { skoru } \leq \mathbf{1 0} \\
\mathbf{n = 1 2 5}\end{array}$ & $\begin{array}{l}\text { Anksiyete } \\
\text { skoru }>\mathbf{1 0} \\
\mathbf{n = 2 4}\end{array}$ & $\mathbf{p}$ \\
\hline Uyku etkinliği \% & $79 \pm 13$ & $75 \pm 17$ & 0,151 \\
\hline Uyku latansı (dakika) & $23 \pm 27$ & $23 \pm 29$ & 0,952 \\
\hline REM latansı (dakika) & $125 \pm 94$ & $125 \pm 87$ & 0,986 \\
\hline $\mathrm{N} 1 \%$ & $6 \pm 5$ & $6 \pm 4$ & 0,982 \\
\hline $\mathrm{N} 2 \%$ & $64 \pm 13$ & $65 \pm 14$ & 0,830 \\
\hline $\mathrm{N} 3 \%$ & $15 \pm 9$ & $15 \pm 10$ & 0,840 \\
\hline $\mathrm{REM} \%$ & $14 \pm 7$ & $14 \pm 7$ & 0,712 \\
\hline AHI ort./SS & $32 \pm 27$ & $31 \pm 32$ & 0,866 \\
\hline Al ort./SS & $20 \pm 26$ & $22 \pm 29$ & 0,707 \\
\hline ODI ort./SS & $27 \pm 26$ & $28 \pm 31$ & 0,826 \\
\hline MinSpO $\%$ & $83 \pm 8$ & $81 \pm 10$ & 0,492 \\
\hline Ortalama SpO $\%$ & $93 \pm 2$ & $91 \pm 8$ & $\mathbf{0 , 0 0 5}$ \\
\hline PLMi ort./SS & $12 \pm 23$ & $13 \pm 19$ & 0,719 \\
\hline $\begin{array}{l}\text { Ort./SS: Ortalama/standart sapma, AHi: Apne hipopne indeksi, Al: Apne } \\
\text { indeksi, ODi: Oksijen desatürasyon indeksi, MinSpO } \\
\text { satürasyonu, Minimum oksijen }\end{array}$ \\
\hline
\end{tabular}

tanımlamıştır. Onu takiben Reynolds ve ark. (5) OUAS'li hastaların \%40'ında, Millman ve ark. (6) \%45'inde depresyon tanımlamıştır. Sonraki yıllarda da pek çok çalışmada bu ilişki gösterilmiş ve OUAS'li hastalarda depresyon oranı \%5-63 gibi değişen oranlarda bulunmuştur (7-14). Ohayon'un (8) çok geniş bir popülasyonu içeren çalışmasında uykuda solunum bozukluğu olan olgularda majör depresif hastalık riski 5,26 kat daha yüksek bulunmuştur. Bu sonuçlarla benzer olarak çalışmamızda olgularımızın \%45'inde depresyon olasılığı muhtemel, \%21'inde depresyon olasıllı̆ı yüksek bulundu.

Çalışmalarda OUAS ile depresyon arasındaki ilişkinin hastalığın şiddeti ile mi yoksa semptomları ile mi ilişkili olduğu konusunda çelişkili sonuçlar mevcuttur. Çünkü OUAS'li hastalarda depresyona yol açan muhtemel birkaç mekanizmadan söz edilmektedir. Gece uyku bölünmesinin seratoninerjik aktiviteyi azaltarak depresyona yol açtığını ileri süren hipotezler yanı sıra hipokseminin de depresyona yol açtığı ileri sürülmektedir (9). Farklı mekanizmalar olması nedeni ile de bazı çalışmalarda depresyonun OUAS şiddeti ile ilişkili olduğu tespit edilmişken bazılarında GAU gibi semptomlarla ilişkili olduğu bulunmuştur. Bu konuda yapılmış ilk çalışmalardan Reynolds ve ark.'nın (5) çalışmasında gündüz uykululuğu daha fazla olan uyku apneli hastalarda depresyonun daha fazla olduğu görülmüş, Millman ve ark.'nın (6) çalışmasında ise ağır OUAS'li hastalarda depresyonun daha fazla olduğu ve sürekli pozitif havayolu basıncı (CPAP) kullanımı ile depresyonun da gerilediği tespit edilmiştir. Daha yakın tarihli iki derlemede de OUAS'li hastalardaki depresyonun hastalığın varlığı ve şiddeti ile ilişkili olduğunu gösterenlerin yanı sıra hastalık şiddetinden bağımsız olarak GAU semptomu ile ilişkili olduğunu gösteren çalışmalar da yer almaktadır $(9,13)$. Depresyonun GAU semptomu ile ilişkili olduğunu destekleyen bazı çalışmalarda da OUAS'li hastalarda CPAP tedavisi ile GAU semptomunun gerilemesi sonucunda depresyon semptomlarının da düzeldiği gösterilmiştir $(13,23,24)$. Bizim çalışmamızda da DS yüksek olan hastalarla DS düşük bulunan hastalar arasında OUAS

Tablo 7. HADS ile demografik özellikler, Epworth uykuluk skalası, polisomnografi bulguları ve gündüz aşırı uykululuk arasındaki korelasyon

\begin{tabular}{|c|c|c|c|c|}
\hline & \multicolumn{2}{|c|}{ Depresyon skoru } & \multicolumn{2}{|c|}{ Anksiyete skoru } \\
\hline & $\mathbf{p}$ & $\mathbf{r}$ & $\mathbf{p}$ & $\mathbf{r}$ \\
\hline Yaş & 0,011 & 0,209 & 0,107 & 0,132 \\
\hline Cinsiyet & 0,015 & 0,199 & $<0,001$ & 0,299 \\
\hline VKI & 0,325 & 0,081 & 0,031 & 0,177 \\
\hline Epworth skoru & 0,063 & 0,153 & 0,039 & 0,170 \\
\hline $\mathrm{AHI}$ & 0,843 & 0,016 & 0,598 & 0,044 \\
\hline $\mathrm{MinSpO}_{2} \%$ & 0,103 & $-0,133$ & 0,227 & $-0,100$ \\
\hline Ortalama $\mathrm{SpO}_{2} \%$ & 0,017 & $-0,196$ & 0,230 & $-0,099$ \\
\hline PLMI & 0,146 & 0,120 & 0,141 & 0,121 \\
\hline Horlama & 0,156 & 0,117 & 0,853 & 0,015 \\
\hline Sabah baş ağrısı & 0,090 & 0,139 & 0,945 & 0,006 \\
\hline Gündüz aşırı uykululuk & 0,521 & 0,053 & 0,032 & 0,176 \\
\hline
\end{tabular}


varlığı ve AHI açısından bir fark bulunmamakla birlikte DS yüksek olan olgularda EUS skoru daha yüksek bulundu.

Literatürde OUAS ve depresyon ilişkisini gösteren çok sayıda çalışma olmasına rağmen, anksiyete ile ilişkisini gösteren daha az sayıda çalışma vardır. Kjelsberga ve ark. (14) çalışmasında HADS kullanılmış ve CPAP kompliansı düşük olan OUAS'li hastalarda hem depresyon hem de AS daha yüksek bulunmuş, GAU daha fazla olanlarda da DS daha yüksek bulunmuştur. Şahbaz ve ark. (12) çalışmasında HADS ile OUAS şiddeti arasında bir ilişki bulunmamıştır. Fakat hem anksiyete hem de DS'leri ile EUS skoru arasında anlamlı ilişki bulunmuş ve semptomları daha uzun süredir devam edenlerde AS'nin de daha yüksek olduğu tespit edilmiştir. Sforza ve ark. (25) çalışmasında da HADS ile $\mathrm{AHI}$ arasında bir ilişki bulunmamış olmakla birlikte EUS skoru yüksek olanlarda ve oksijen satürasyonu düşük olanlarda HADS daha yüksek bulunmuştur. Bizim çalışmamızda bu çalışmalara benzer olarak HADS kullanılmış olup DS yüksek olanlarda EUS skoru daha yüksek, AS yüksek olanlarda da minimum oksijen satürasyonu daha düşük bulundu. Korelasyon analizlerinde de AS'leri ile EUS skoru ve GAU semptomu arasında pozitif korelasyon, DS'leri ile ortalama oksijen satürasyonu arasında negatif korelasyon mevcuttu.

Bazı çalışmalarda kadın OUAS'li hastalarda depresyon oranının daha fazla olduğu tespit edilmiştir $(26,27)$. Çalışmamızda da korelasyon analizlerinde hem DS hem de AS ile kadın cinsiyet arasında pozitif korelasyon mevcuttu. OUAS'li hastalardaki depresyonun uyku mimarisindeki bozulma, uyku ve REM latansındaki uzama ile ilişkili olduğunu gösteren çalışmalar mevcuttur (9). Çalışmamızda uyku mimarisi ile HADS arasında ilişki bulunmadı. Bardwell ve ark.'nın (28) çalışmasında OUAS ve depresyon arasındaki ilişkinin VKI, yaş ve hipertansiyon ile korele olduğu tespit edilmiş. Bizim çalışmamızda da DS ile yaş, AS ile VKI arasında korelasyon bulunduğu gibi DS yüksek olanlarda astım hastalığı daha yüksek oranda bulundu.

Çalışmamızın kısıtlayıcı yönlerinden biri, tek merkezli olup sonuçların genellenemeyeceğidir. Diğer yandan depresyon ve AS'leri yüksek bulunan hastalar, psikiyatri ile konsülte edilmemiştir. Fakat literatüre bakıldığında çalışmaların çoğunda hastaların depresyon ve anksiyete durumları kullanılan ölçeklerle belirlenmiştir ve kullandığımız HADS uluslararası kabul görmüş ve Türkçe uyumluluğu da kanıtlanmış bir skaladır (15-17).

Çalışmamızın amacı HADS skorları ile semptomlar ve PSG bulguları arasındaki ilişkiyi incelemek olduğu için uyku laboratuvarına OUAS'nin majör semptomlarının biri veya tümü ile başvuran ve $\mathrm{PSG}^{\prime}$ de $\mathrm{AHI}>5$ veya $\leq 5$ bulunan tüm olgular birlikte değerlendirilmiştir. Çünkü $\mathrm{AHI} \leq 5$ olan olgular da en azından horlama veya GAU semptomu ile başvurmuştur. Çalışmamızın sonucunda da yüksek HADS'nin OUAS varlığı ve şiddeti ile değil yaş, kadın cinsiyet, astım hastalığı, VKì, EUS skoru ve GAU semptomu ile korelasyon gösterdiği tespit edilmiştir.

\section{Sonuç}

Horlama, tanıklı apne ve GAU semptomları ile uyku laboratuvarına başvuran hastalarda hastane anksiyete depresyon skalası ile tespit edilen yüksek depresyon ve anksiyete skorları AHI ile ilişkili bulunmadı. GAU semptomu, depresyon ve anksiyete gelişmesinde rol oynayan en önemli semptom olarak tespit edildi. Bu nedenle uyku laboratuvarına başvuran olgularda semptomların ayrıntılı olarak sorgulanması, EUS'nin yanı sıra HADS'nin de uygulanması ile hastaların duygusal durumlarının daha iyi anlaşılması, tedavi kararını ve hastaların tedavi konusunda ikna edilmesini kolaylaştıracaktır. Anksiyete ve depresyonu etkileyen yaş, kadın cinsiyet, ek hastalıklar gibi pek çok faktörün bulunması da bu konuda yapılacak daha geniş popülasyonlu çalışmalara ihtiyaç olduğunu düşündürmektedir.

Etik

Etik Kurul Onayı: Anket çalışması olduğu için etik kurul onayı alınmamıştır, Hasta Onayı: Alınmıştır.

Hakem Değerlendirmesi: Editörler kurulu tarafından değerlendirilmiştir.

\section{Yazarlık Katkıları}

Cerrahi ve Medikal Uygulama: Banu Salepçi, Gülten Aktin Güngör, Elif Torun Parmaksız, Konsept: Banu Salepçi, Sevda Şener Cömert, Dizayn: Banu Salepçi, Nesrin Kıral, Veri Toplama veya İşleme: Gülten Aktin Güngör, Ali Fidan, Coşkun Doğan, Analiz veya Yorumlama: Banu Salepçi, Ali Fidan, Literatür Arama: Elif Torun Parmaksız, Sevda Şener Cömert, Coşkun Doğan, Yazan: Banu Salepçi, Elif Torun Parmaksız, Nesrin Kıral. Çıkar Çatışması: Yazarlar tarafından çıkar çatışması bildirilmemiştir.

Finansal Destek: Yazarlar tarafından finansal destek almadıkları bildirilmiştir.

\section{Kaynaklar}

1. Sleep-related breathing disorders in adults: recommendations for syndrome definition and measurement techniques in clinical research. The Report of an American Academy of Sleep Medicine Task Force. Sleep 1999;22:667-89.

2. Adult Obstructive Sleep Apnea Task Force of the American Academy of Sleep Medicine. Clinical Guideline for the Evaluation, Management and Long-term Care of Obstructive Sleep Apnea in Adults. J Clin Sleep Med 2009;5:263-76.

3. Young T, Palta M, Dempsey J, Skatrud J, Weber S, Badr S. The occurence of sleep-disordered breathing among milde-aged adults. N Eng J Med 1993;328:1230-5.

4. Guilleminault C, Eldridge FL, Tilkian A, Simmons FB, Dement WC Sleep apnea syndrome due to upper airway obstruction: a review of 25 cases. Arch Intern Med 1977; 137:296-300.

5. Reynolds CF, Kupfer DJ, McEachran AB, Taska LS, Sewitch DE, Coble PA. Depressive psychopathology in male sleep apneics. J Clin Psychiatry 1984;45:287-90

6. Millman RP, Fogel BS, McNamara ME, Carlisle CC. Depression as a manifestation of obstructive sleep apnea: reversal with nasal continuous positive airway pressure. J Clin Psychiatry 1989;50:348-51 .

7. Akashiba T, Kawahara S, T.Akahoshi, Omori C, Sahito O, Majima T, Horio T. Relationship between quality of life and mood or depression in patients with severe obstructive sleep apnea syndrome. Chest 2002; 122:861-5.

8. Ohayon MM. The effects of breathing-related sleep disorders on mood disturbances in the general population. J Clin Psychiatry 2003;64:1195-200; quiz, 1274-6.

9. Schröder CM, O'Hara R. Depression and Obstructive Sleep Apnea (OSA). Ann Gen Psychiatry 2005;4:13.

10. El-Ad B, Lavie P. Effect of sleep apnea on cognition and mood. Int Rev Psychiatry 2005; 17:277-82.

11. BaHammam AS, Kendzerska T, Gupta R, Ramasubramanian C, Neubauer DN, Narasimhan M, Pandi-Perumal SR, Moskowitch A. Comorbid depression in obstructive sleep apnea: an underrecognized association. Sleep Breath 2016;20:447-56. 
12. Şahbaz S, Itil O, Inönü H, Öztura I, Yemez B, Baklan B, Etikan I, Seyfikli Z. Quality of life, frequency of anxiety and depression in obstructive sleep apnea syndrome. Tur Toraks Der 2008;9:141-5.

13. Ejaz SM, Khawaja IS, Bhatia S, Hurwitz TD. Obstructive Sleep Apnea and Depression: A Review. Innov Clin Neurosci 2011;8:17-25.

14. Kjelsberga FN, Ruuda EA, Stavema K. Predictors of symptoms of anxiety and depression in obstructive sleep apnea. Sleep Med 2005;6:341-6.

15. Zigmond AS, Snaith RP. The Hospital Anxiety And Depression Scale. Acta Psychiatr Scand 1983;67:361-70.

16. Snaith RP. The Hospital Anxiety And Depression Scale. Health Qual Life Outcomes 2003;1:29.

17. Aydemir Ö, Güvenir T, Küey L, Kültür S. Hastane Anksiyete ve Depresyon Ölçeği Türkçe Formunun Geçerlilik ve Güvenilirlik Çalışması. Türk Psikiyatri Dergisi 1997;8:280-7.

18. Iber C. The AASM manual for the scoring of sleep and associated events. Rules, terminology and technical specifications. AASM, Westchester; 2007.

19. Grig-Damberger M. The AASM Scoring Manuel Four Years Later. J Clin Sleep Med 2012;8:323-32.

20. American Academy of Sleep Medicine. International Classification of Sleep Disorders. 3rd ed (ICSD-3). Westchester: American Academy of Sleep Medicine, 2014.

21. Johns MW. A new method for measuring daytime sleepiness: The Epworth Sleepiness Scale. Sleep 1991;14:540-5.
22. Izci B, Ardic S, Firat H, Sahin A, Altinors M, Karacan I. Reliability and validity studies of the Turkish version of the Epworth Sleepiness Scale. Sleep Breath 2008;12:161-8.

23. Habukawa M, Uchimura N, Kakuma T, Yamamoto K, Ogi K, Hiejima $\mathrm{H}$, Tomimatsu $\mathrm{K}$, Matsuyama S. Effect of CPAP treatment on residual depressive symptoms in patients with major depression and coexisting sleep apnea: Contribution of daytime sleepiness to residual depressive symptoms. Sleep Med 2010;11:552-7.

24. El-Sherbini AM, Bediwy AS, El-Mitwalli A. Association between obstructive sleep apnea (OSA) and depression and the effect of continuous positive airway pressure (CPAP) treatment. Neuropsychiatr Dis Treat 2011;7:715-21.

25. Sforza E, de Saint Hilaire Z, Pelissolo A, Rochat T, Ibanez V. Personality, anxiety and mood traits in patients with sleep-related breathing disorders: effect of reduced daytime alertness. Sleep Med 2002;3:139-45.

26. Pillar G, Lavie P. Psychiatric symptoms in sleep apnea syndrome. Chest 1998;114:697-703.

27. Enright PL, Newman AB, Wahl PW, Manolio TA, Haponik EF, Boyle PJ. Prevalence and correlates of snoring and observed apneas in 5,201 older adults. Sleep 1996;19:531-8.

28. Bardwell WA, Berry CC, Ancoli-Israel S, Dimsdale JE. Psychological correlates of sleep apnea. J Psychosom Res 1999;47:583-96. 